\title{
MODELING OF DISPERSION MAGNETIC FIELDS DEVELOPED BY THE MAIN ELECTROMAGNETIC SYSTEMS USED ON MILITARY SHIPS
}

\author{
V. SOLCANU ${ }^{1}$, M. GAICEANU ${ }^{1}$, M. CONSTANTINESCU ${ }^{2}$, GHE. SAMOILESCU ${ }^{2}$, A. SOTIR ${ }^{2}$ \\ ${ }^{1}$ Dunarea de Jos University of Galati, 800008, Romania, ${ }^{2}$ Naval Academy "Mircea cel Batran", Constanta, Romania \\ E-mail: vasilesolcanu@dedeman.ro, marian.gaiceanu@ugal.ro,gheorghe.samoilescu@anmb.ro
}

\begin{abstract}
In this paper, the authors present the modelling methods and numerical calculation of the dispersion magnetic field of electrical machines, as well as the results of their validation through practical measurements. An adequate analytic formula for magnetic induction calculation is proposed by the authors. The experimental results validate the proposed analytic model. Moreover, the proposed model is valid for both near and far field regions.
\end{abstract}

Keywords: electric machine, magnetic flux leakage, magnetic flux density, magnetic field measurements, electromagnetic compatibility.

\section{INTRODUCTION}

Transient processes in electrical machines can lead to both increased magnetic flux leakage and electric fields than in the steady state operation. The frequency range of these fields is within the range $50 \ldots 10^{5} \mathrm{~Hz}$, and the pulse duration is of the order of $10^{-8} \ldots 10^{-7}(\mathrm{~s})$ [1-3].

However, the study of the external magnetic flux leakage of DC and AC electrical machines are on-going [4]. In the electromagnetic compatibility (EMC) study field, the importance of magnetic fields studying (analyse and measure) becomes stringent when the density of electrical and electronic equipment is particularly high, such as industrial environments, operating theatres and especially aboard military ships [5-7].

Because most part of the low frequency electromagnetic field energy can be found in the magnetic component, the corresponding fields will lead to an increased ship's magnetic signature. Therefore, an increased vulnerability of military ships is obtained, becoming a stringent security issue for all military ships participating into theatres of operations [8-10].

\section{THEORETICAL CONSIDERATIONS}

Electric machines are complex electromagnetic systems having a wide variety of constructive solutions and operating principles. Therefore, practically, the analytical calculation of the magnetic field of dispersion is laborious, and sometimes impossible. In the specialized literature, very few references are made to the dispersion inductances of electric machines (DC and AC) [11-13], and the same to the calculation of the magnetic field of dispersion [12]. In practice, most of the time the empirical relationships methodology is applied as a result of the actual measurement results processing.

The recommended procedures [3, 4] in the field deliver the expression of an empirical relation in the following form

$$
\frac{B}{B_{0}}=A \cdot\left(\frac{R_{0}}{R}\right)^{n}
$$

where:

- $\quad B_{0}$ and $B$ represents the magnetic inductions at the points, relative to the geometric center of the source of disturbances, at distances $R_{0}$ and $R$ respectively, like in Figure 1;

- $\quad A$ is an empirical coefficient,

- $\quad n$ is an exponent that has different values, depending on the type of the electric machine.

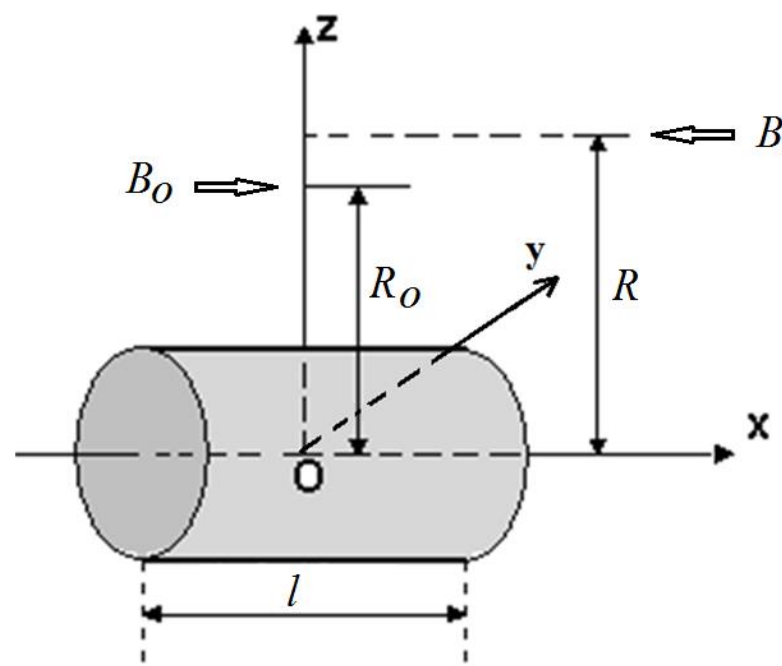

Figure 1. Magnetic inductions $B$ and $B o$, at distances $R$ and $R o$ measured from the center of the electric machine/ source of disturbances

From the rotating electric machines point of view, in some technical literature $([3],[14])$ it is proposed the determination of the alternative component of the magnetic induction corresponding to the dispersion magnetic field of perturbation:

$$
B=A \cdot R^{-3 / 2}
$$


where:

$-R[\mathrm{~cm}]$ is the distance from the observation point to the electric machine case,

- $A$ is an experimentally deduced coefficient that can take the following values:

- $A=445$ for AC rotary electric machines,

- $A=93$ for DC rotary electric machines.

A relation that leads to appropriate results for near region from the observation point to the field source is of the form delivered in [3], [11] as follows:

$$
B=B_{0}\left(\frac{R_{0 C}}{R c}\right)^{3 / 2}
$$

where:

- $B_{0}$ is the value of the magnetic induction measured at the distance $R_{0}$ from the electric machine case,

- $\quad$ and $B$ is the value of the magnetic induction to be determined corresponding to the distance to the housing of the electric machine $R c>R_{O C}$ (Figure 2).

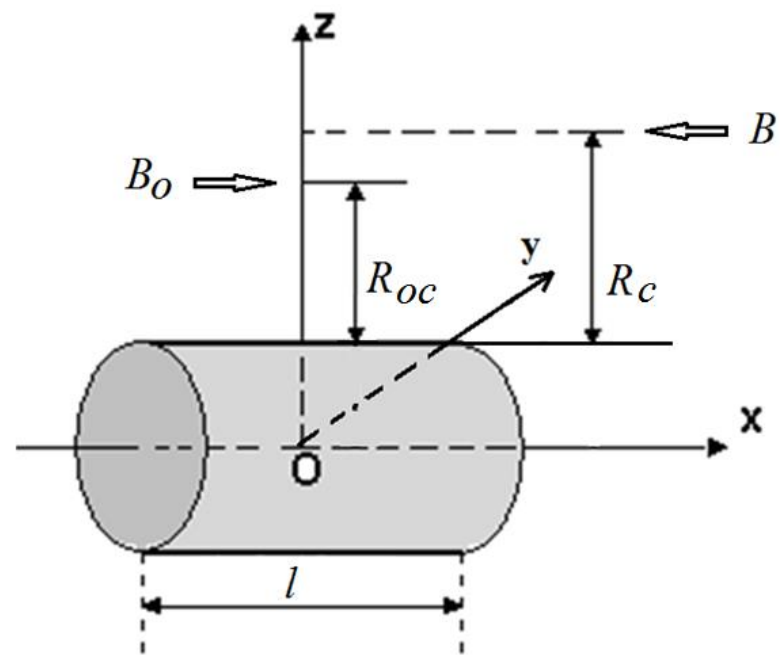

Figure 2. Magnetic Inductions $B$ and $B o$ at distances $R c$ and $R o c$ measured from the electric machine case/ source of disturbances

For the different converter groups formed by two rotating electric machines, the value of the magnetic induction in the environment is given by the geometric sum of the fields created by each electric machine.

For the converter group, consisting of two electric current machines, the value of the magnetic induction in the environment, considering the empirical relation (2), is calculated as follows [11]:

$$
B=\sqrt{B_{1}^{2}+B_{2}^{2}}=A \sqrt{2} R c^{-3 / 2}=445 \sqrt{2} R c^{-3 / 2}
$$

in which $R c$ is expressed in $c m$, and $B$ is obtained in $\mu T$.

\section{MEASUREMENT METHODOLOGY. MEASUREMENT RESULTS.}

In order to verify the relations (2) and (3), measurements were made on a three-phase asynchronous motor with the rotor in short circuit with the following technical parameters: $P_{n}=7 \mathrm{~kW} ; \quad U_{n}=380 \mathrm{~V} ; \quad n_{n}=1460 \quad$ r.p.m.; $\cos \varphi_{n}=0.84 ; f_{n}=50 \mathrm{~Hz} ; l=0,46 \mathrm{~m}$.

It has been considered that the electric machine from the point of view of the dispersion magnetic field has a meridian plane symmetry, and correspondingly, it is framed in a system of rectangular axes with the origin of the coordinates in the geometric center, the abscise $\mathrm{Ox}$ as the axial line of the machine, the axis Oy as the transversal axis, and $\mathrm{Oz}$ as the vertical axis, depicted in Figure 1.

By measuring the average value of the magnetic induction on the generator of a cylinder that includes the electric machine, it is found that the values do not remain constant, but remain of the same order of magnitude. For example, for the considered electric motor, when operating under load, at a distance from the electrical machine case equal to $R c=0,150 \mathrm{~m}$, the average values of the magnetic induction, on generators, are between $18 \mu T$ and $24 \mu T$. Higher values are in the coil ends area.

By making measurements on an transversal axis to the electrical machine housing, located half on its length $(\mathrm{Oz}$ axis, Figure 2), at a point relative to the electrical machine housing, at the distance $R_{0 c}=0,105$, the average value of magnetic induction $B_{0}=56 \mu \mathrm{T}$ was obtained.

In Figures 3, 4 and 5, different variations of the magnetic induction $\mathrm{B}$ as a function of distance are shown (continuous red line), based on the values obtained by measurement and with blue line the variation of magnetic induction $\mathrm{B}$ as a function of distance, deduced based on formulas (2) and (3). The interpolated data values have been obtained by using "lspline" MATHCAD function, which performs a cubic spline interpolation with linear termination conditions.

Taking into account the variation of the magnetic induction (Figure 3), a significant variation of the magnetic field can be observed for distance values that do not exceed 1,5 times the dominant geometric dimension of the source $(46 \mathrm{~cm} \times 1.5=69 \mathrm{~cm})$, that is for the near field area. At the same time, it is observed that the relation (2) offers excellent results only for the determination of the magnetic induction values in the far field region of the rotating electric machines, in the near field area appearing significant errors. 


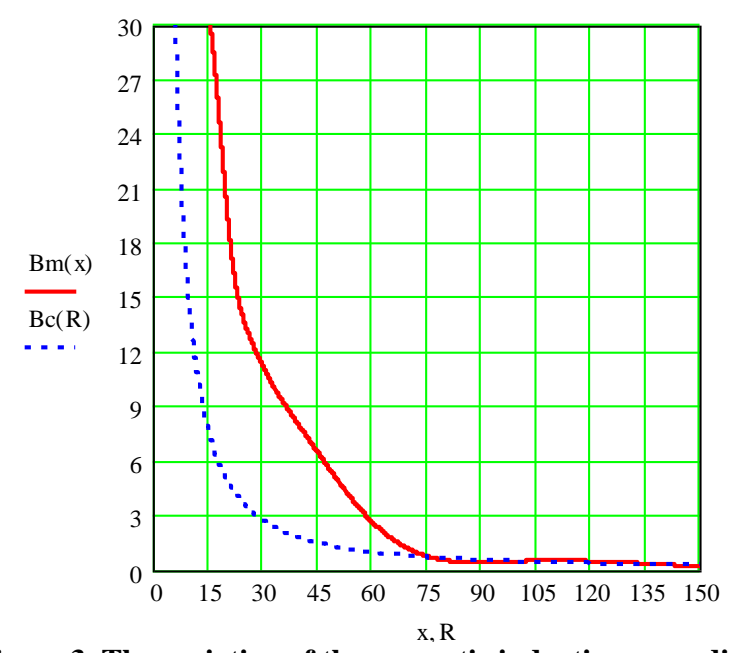

Figure 3. The variation of the magnetic induction according to the distance from the source for an $\mathrm{AC}$ machine: with blue dotted line - $B c(R)$ - the values calculated with relation (2) for $A=445$ and with red continuous line - $B m(x)$ - the values obtained by measurements

In Figure 4 the results obtained by measurements are represented with a continuous line, and the values obtained based on the relation with a dashed line (3). Comparing the two curves it is found that, for the near field area, the relation (3) provides the approximate result identical to those obtained by measurements.

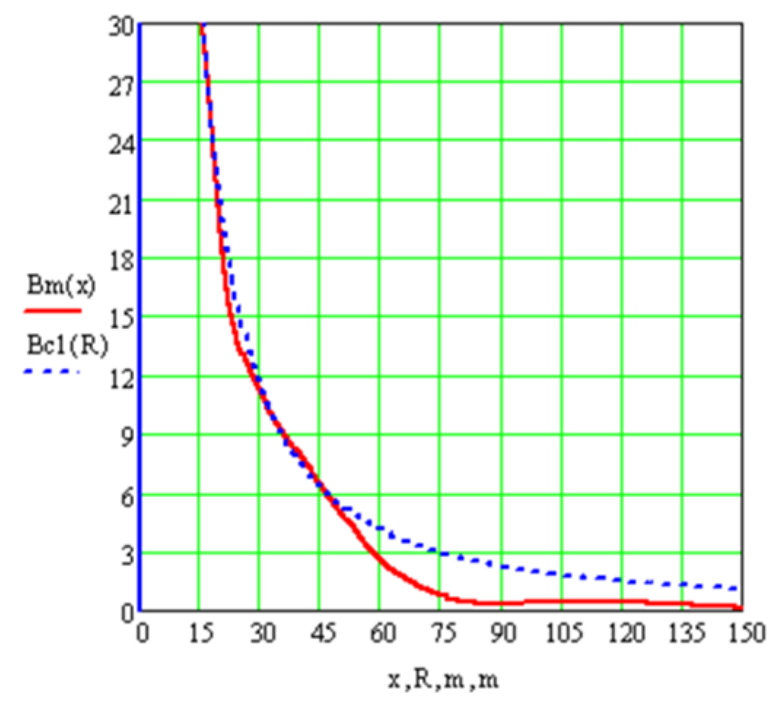

Figure 4. Induction variation as a function of distance from source for an AC machine: with blue dotted line - Bc1 (R) values calculated with relation (3) and with red continuous

line - Bm $(x)$ - values obtained by measurements;

In order to find the more precise results, the formula (2) had been modified adequately by the authors. Therefore, for the near field region, different values of coefficient $A$ have been chosen through tests. For the near field area, the best value results were obtained by choosing 1.800 value for the $A$ coefficient. The comparative results are illustrated in Figure 5.

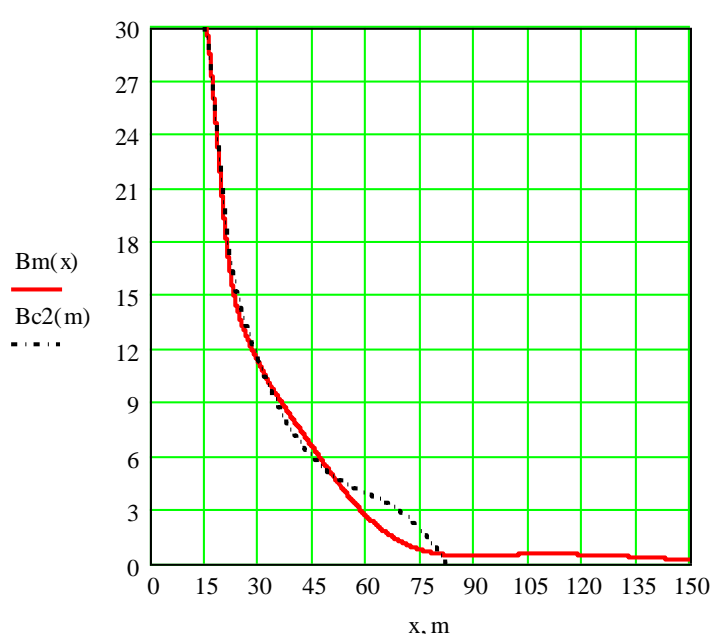

Figure 5. Magnetic induction variation as a function of distance from source for an $\mathrm{AC}$ machine: with blue dotted line $-B c 2(R)$ - the values calculated with the relation (2) for a corrected value of the coefficient $A=\mathbf{1 . 8 0 0}$

According to those presented in Figure 5, it turns out that, for alternating current rotary machines, the relation (2) can be used for the near field region if it is adopted for the coefficient $A$ the value of 1.800 , and for the far field the value of 445 .

In order to verify the relationship (4), measurements have been made on the ATT20-500M converter group, consisting of an asynchronous motor with the short-circuit rotor $\left(U_{n}=380 \mathrm{~V}, I_{n}=49,5 \mathrm{~A}, f_{n}=50 \mathrm{~Hz}, n_{n}=2920 \mathrm{RPM}\right)$ and a synchronous generator $\left(U_{n}=230 \mathrm{~V}, I_{n}=62,7 \mathrm{~A}, f_{n}=500\right.$ $\mathrm{Hz}$ ).

Following the measurements, it found that the relation (4) can be used to calculate the magnetic induction only for the far field area. Even under these conditions, the errors between the calculated and measured values are over $10 \%$. For example, when carrying out measurements at a distance of $200 \mathrm{~cm}$ from the electrical machine case, perpendicular to the electrical machine case, the $B_{\text {med }}=$ $0,20 \mu T$ magnetic induction average value was obtained.

By using the relation (4), and considering $R=$ $200 \mathrm{~cm}$, the following relation is obtained:

$$
B_{\text {med }}=445 \sqrt{2}(200)^{-3 / 2}=0,2225 \mu \mathrm{T}
$$

\section{CONCLUSIONS}

From measurement results it follows that the empirical relation (2) leads to the exact values if the distance of the point at which the value of the magnetic induction is calculated exceeds at least twice the length of the electric machine (which is the dominant dimension).

For the presented study in this paper, the relation (2) produces excellent results and for the near field if it is adopted $A=1800$ coefficient value.

Considering that the introduction of a test body/measuring sensor in the near field area of an electric machine changes 
the value of the fields themselves by the appearance of the inductive and capacitive couplings, for the validation of the proposed value of the coefficient $A$ several measurements must be made on different types of AC rotary electric machines with different sensor types.

The relation (3) allows the determination of the dispersion magnetic field, based on an effective measurement $\left(B_{0}\right.$ at the distance $R_{0}$ of the source), with a good accuracy for both the far field area, and with a very good accuracy for the near field area.

The relation (4) can be used in the calculation of the external magnetic fields of the converter groups, with an accuracy within $10 \%$ only for the far field area.

In the case of converter groups, for the near field area, the measured values cannot be obtained by mathematical relations due to the non-uniformity of the magnetic circuit of the machine and the impossibility of establishing an equivalent magnetic circuit for the calculation of the magnetic induction.

The measured magnetic induction average values, at near distances (the distance to the housing of the electric machine smaller than twice its dominant geometric dimension) are large, and this aspect is of interest to the command and control communications system because under no circumstances, the cable paths of these systems should not pass through these areas.

\section{REFERENCES}

[1] Mincu C, T. Gruia., Compatibilitatea sistemelor radioelectronice. Bucureşti: Editura Olimp, 1999.

[2] Sotir, Al., Interferente electromagnetice perturbatoare - Baze teoretice, Bucuresti: Editura Militara, 2005.

[3] Rusin I.S., Electropitanie hidroacusticescoi aparaturâ. Leningrad: ED. Sudostraenie, 1975.

[4] Brudny J-F, Jean-Philippe Lecointe, Fabrice Morganti, Farid Zidat, and Raphaël Romary, Use of the External Magnetic Field for Induction Distinction, IEEE TRANSACTIONS ON MAGNETICS, VOL. 46, NO. 6, Univ Lille Nord de France, F-59000 Lille, France: s.n., JUNE 2010.

[5] Solcanu V., Gaiceanu M., The method of compensating non -linear effects due to disturbing signals in the military operations theatres, Resita: Analele Universitatii "Eftimie Murgu", Fascicula de Inginerie Vol. 26, No. 1, pag. 213-220, ISSN 1453 7397, 2019.

[6] Solcanu V., Gaiceanu M., Sotir A., Samoilescu G., Constantinescu M., The results of the electromagnetic field measurements performed on a military maritime ship to determine the effectiveness of a radio-absorbent material, 6th International Symposium on Electrical and Electronics Engineering (ISEEE), Galati, 2019.

[7] Solcanu V, Gaiceanu M, Solomon M., Interference Challenges on board Military Ships, 6th International
Symposium on Electrical and Electronics Engineering (ISEEE), Galati, 2019.

[8] Roytgarts, Mr. Mikhail, External Magnetic Fields of Powerful Generators, International Conference on Renewable Energies and Power Quality (ICREPQ'12) 28th to, 30th March, Santiago de Compostela (Spain), 2012.

[9] Rosu G., Samoilescu G., Baltag O., Radu S, Iorgulescu D., The effect of a magnetic treatment on ship magnetic signature, 2014 International Symposium on Fundamentals of Electrical Engineering (ISFEE), Bucharest, 2014, pp. 1-6. doi: 10.1109/ISFEE.2014.7050637.

[10] Rapoarte de cercetare in cadrul Programului Naţional CERES: „Reducerea amprentei magnetice a navei militare în scopul protecţiei împotriva câmpurilor de mine marine", 2003-2005.

[11] Hasril N., Mahdi C. I, Mohd Moesli Muhammad, Irwan Mohd N., Management of Naval Vessel's Electromagnetic Signatures: A Review of Sources and Countermeasures, November 2013, Defence S and T Technical Bulletin 6(2):93-110.

[12] NAVSEA 0967-LP-000-0160, Electronics Installation and Maintenance Book.

[13] Mahdi C. I, Hasril Nain, Nik Hassanuddin, Mohd Hambali A., An overview of ship magnetic signature and silencing technologies, December 2019, DOI: 10.13140/RG.2.2.14643.58401, Lab: Abdul Rauf. Abdul Manap's Lab.

[14] Rapoarte de cercetare in cadrul Programului Naţional CEEX 2005: "Ecologie Electromagnetica caracterizarea surselor, diagnosticarea efectelor, prevenirea si combaterea lor", 2005-2008. 